\title{
Analysis of Vibration of the Euler-Bernoulli Pipe Conveying Fluid by Dynamic Stiffness Method and Transfer Matrix
}

\author{
Yunfeng $\mathrm{Li}^{1}$, Yundong $\mathrm{Li}^{2}$, Naveed Akbar ${ }^{2}$ \\ ${ }^{1}$ School of Automation \& Information Engineering, Sichuan University of Science \& Engineering, Zigong, China \\ ${ }^{2}$ School of Mathematics and Statistics, Sichuan University of Science \& Engineering, Zigong, China \\ Email: ${ }^{*}$ lyd1114@126.com
}

How to cite this paper: Li, Y.F., Li, Y.D. and Akbar, N. (2020) Analysis of Vibration of the Euler-Bernoulli Pipe Conveying Fluid by Dynamic Stiffness Method and Transfer Matrix. Journal of Applied Mathematics and Physics, 8, 172-183.

https://doi.org/10.4236/jamp.2020.81013

Received: December 9, 2019

Accepted: January 14, 2020

Published: January 17, 2020

Copyright $\odot 2020$ by author(s) and Scientific Research Publishing Inc. This work is licensed under the Creative Commons Attribution International License (CC BY 4.0).

http://creativecommons.org/licenses/by/4.0/

\begin{abstract}
The dynamic stiffness method and Transfer method is applied to study the vibration characteristics of the Euler-Bernoulli pipe conveying fluid in this paper. According to the dynamics equation of the pipe conveying fluid, the element dynamic stiffness is established. The vibration characteristic of the single-span pipe is analyzed under two kinds of boundary conditions. The results compared with the literature, which has a good consistency. Based on this method, natural frequency and the critical speed of the two types of multi-span pipe are deserved. This paper shows that the dynamic stiffness method and transfer matrix is an effective method to deal with the vibration problem of pipe conveying fluid.
\end{abstract}

\section{Keywords}

Dynamic Stiffness, Transfer Matrix, Euler-Bernoulli Pipe

\section{Introduction}

Fluid-solid coupled vibration of infusion pipelines exists in the nuclear industry, petroleum industry, and the aviation industry. Over the years, many scholars have done a lot of research work in the dynamic analysis of pipe conveying fluid, especially Paidoussis [1] has achieved many results in linear and nonlinear dynamic analysis of pipe conveying fluid. In engineering, the linear vibration of pipe conveying fluid is also widely used. Many scholars have studied the linear vibration of pipe conveying fluid from different angles. In the early days, scholars [2] [3] generally used a hypothetical modal method or Galerkin method to analyze the vibration of pipe conveying fluid, which is also a popular method for 
dynamic analysis. Recently, Zhang [4] analyzed the vibration of a single-span vibration by using the characteristic method. Huang [5] analyzed the natural frequency of the vibration under different boundary conditions by using the Elimination Galerkin method. Lee [6] made a dynamic analysis of the pipe conveying fluid using the spectral method and discussed the stability of the spectral method. Q. Ni [7] studied the vibration problems of pipe conveying fluid under various boundary conditions using differential transformation method. For the linear vibration problems of complex pipe systems, Sreejith [8] analyzed the vibration problems of curved pipes using the finite element method. Q. Ni [9] used the differential quadrature method to solve the linear vibration problem of infusion curved pipes. Wu and Shih [10] applied the transfer matrix method to analyze the vibration of multi-span simply supported pipe conveying fluid. Chen Zhengxiang and Zhang Weiheng [11] used the finite element method to analyze the stability of multi-span elastic support pipes. Li-Bao Hui [12] used the dynamic stiffness method to analyze the Timoshenko beam multi-span pipe conveying fluid. Later, scholars further studied the multi-span structure [12]-[17] and dynamic stiffness method [18] [19] [20] [21].

Based on the above introduction, we can get that the research on the analysis method of pipe conveying fluid vibration is a hot spot. In this article, the dynamic stiffness method [22] [23] is used to study Euler-Bernoulli beam vibration problems. Based on the dynamic equation of the pipe conveying fluid, this paper uses the dynamic stiffness method to analyze the vibration of the single-span pipe conveying fluid under different boundary conditions. Combining the dynamic stiffness method with the transfer matrix method, the vibration problems of non-periodic and periodic multi-span pipes conveying fluid are analyzed.

In this paper, the first section is exposed to research background of this paper's work and the structure of this paper. Section 2 introduces the unit dynamic stiffness of the infusion pipeline. In Section 3, numerical experiments were conducted under different working conditions, and the corresponding frequencies and critical velocity were obtained and discussed. In Section 4, some conclusions are reached.

\section{Element Dynamic Stiffness of Pipe Conveying Fluid}

First, some system parameters of the pipe are given in Table 1.

Table 1. Some system parameters.

\begin{tabular}{cccc}
\hline system parameter & symbol & system parameter & symbol \\
\hline elastic modulus of pipe & $E$ & Section moment & $I$ \\
transverse displacement of pipe & $W$ & fluid velocity & $U$ \\
fluid mass per unit length & $m_{f}$ & pipe mass per unit length & $m_{p}$ \\
vibration frequency & $\Omega$ & angle of section & $\theta$ \\
bending moment & $M$ & Shear force & $Q$ \\
\hline
\end{tabular}


For infusion straight pipes, ignoring the effects of gravity, internal resistance, externally applied tension, and pressure, the equation of motion can be expressed as [1],

$$
E I \frac{\partial^{4} w}{\partial x^{4}}+m_{f} U^{2} \frac{\partial^{2} w}{\partial x^{2}}+2 m_{f} U \frac{\partial^{2} w}{\partial x \partial t}+\left(m_{f}+m_{\rho}\right) \frac{\partial^{2} w}{\partial t^{2}}=0
$$

In which $E I$ is the bending stiffness of the pipe, $m_{f}$ is the fluid mass of the pipe element, $m_{\rho}$ is the pipe mass of the element, $U$ is the fluid velocity, and $w$ is the lateral displacement of the pipe. For a constant flow velocity, the solution of Equation (1) can be expressed as:

$$
w(x, t)=f(x) \exp (i \Omega t)
$$

where $\Omega$ is the vibration frequency of the pipe conveying fluid. When the pipe is in free vibration, it is uncertain. Substituting Equation (2) into (1), we obtain the fourth-order ordinary differential equation

$$
E I \frac{\mathrm{d}^{4} f}{\mathrm{~d} x^{4}}+m_{f} U^{2} \frac{\mathrm{d}^{2} f}{\mathrm{~d} x^{2}}+2 i U \Omega m_{f} \frac{\mathrm{d} f}{\mathrm{~d} x}-\Omega^{2}\left(m_{f}+m_{\rho}\right) f=0
$$

The solution of Equation (3) has the following form:

$$
f(x)=\sum_{n=1}^{4} A_{n} \mathrm{e}^{i k_{a n} x}
$$

where $k_{a n}(n=1,2,3,4)$ is the complex root of the following equation:

$$
E I k_{a}^{4}-m_{f} U^{2} k_{a}^{2}-2 U \Omega m_{f}-\Omega^{2}\left(m_{f}+m_{\rho}\right)=0
$$

From the beam bending theory, displacement $w$, section angle $\theta$, bending moment $M$, and shear force $Q$ can be expressed as:

$$
\begin{aligned}
& w=f(x) \exp (i \Omega t), \theta=w^{\prime}=f^{\prime}(x) \exp (i \Omega t) \\
& M=E I w^{\prime \prime}=E I f^{\prime \prime}(x) \exp (i \Omega t), Q=E I w^{\prime \prime \prime}=-E I f^{\prime \prime \prime}(x) \exp (i \Omega t)
\end{aligned}
$$

Using Equation (6), we can establish the element node displacement and the node displacement column vector is $\boldsymbol{U}=\left[w_{1 l}, \theta_{1 l}, w_{2 R}, \theta_{2 R}\right]_{e}^{\mathrm{T}}$,

$$
\left[\begin{array}{c}
w_{1 l} \\
\theta_{1 l} \\
w_{2 R} \\
\theta_{2 R}
\end{array}\right]=\left[\begin{array}{cccc}
\mathrm{e}^{i k_{a 1} x_{l}} & \mathrm{e}^{i k_{a 2} x_{l}} & \mathrm{e}^{i k_{a 3} x_{l}} & \mathrm{e}^{i k_{a 4} x_{l}} \\
i k_{a 1} \mathrm{e}^{i k_{a 1} x_{l}} & i k_{a 2} \mathrm{e}^{i k_{a 2} x_{l}} & i k_{a 3} \mathrm{e}^{i k_{a 3} x_{l}} & i k_{a 4} e^{i k_{a 4} x_{l}} \\
\mathrm{e}^{i k_{a 1} x_{R}} & \mathrm{e}^{i k_{a 2} x_{R}} & \mathrm{e}^{i k_{a 3} x_{R}} & \mathrm{e}^{i k_{a 4} x_{R}} \\
i k_{a 1} \mathrm{e}^{i k_{a 1} x_{R}} & i k_{a 2} \mathrm{e}^{i k_{a 2} x_{l}} & i k_{a 3} \mathrm{e}^{i k_{a 3} x_{R}} & i k_{a 4} \mathrm{e}^{i k_{a 4} x_{R}}
\end{array}\right]\left[\begin{array}{c}
A_{1} \\
A_{2} \\
A_{3} \\
A_{4}
\end{array}\right] \exp (i \Omega t)
$$

Equation (7) can be simplified as follows:

$$
\boldsymbol{U}=\boldsymbol{C A}
$$

where:

$$
\boldsymbol{C}=\left[\begin{array}{cccc}
\mathrm{e}^{i k_{a 1} x_{l}} & \mathrm{e}^{i k_{a 2} x_{l}} & \mathrm{e}^{i k_{a 3} x_{l}} & \mathrm{e}^{i k_{a 4} x_{l}} \\
i k_{a 1} \mathrm{e}^{i k_{a 1} x_{l}} & i k_{a 2} \mathrm{e}^{i k_{a 2} x_{l}} & i k_{a 3} \mathrm{e}^{i k_{a 3} x_{l}} & i k_{a 4} \mathrm{e}^{k_{a 4} x_{l}} \\
\mathrm{e}^{i k_{a 1} x_{R}} & \mathrm{e}^{i k_{a 2} x_{R}} & \mathrm{e}^{i k_{a 3} x_{R}} & \mathrm{e}^{i k_{a 4} x_{R}} \\
i k_{a 1} \mathrm{e}^{i k_{a 1} x_{R}} & i k_{a 2} \mathrm{e}^{i k_{a 2} x_{l}} & i k_{a 3} \mathrm{e}^{i k_{a 3} x_{R}} & i k_{a 4} \mathrm{e}^{i k_{a 4} x_{R}}
\end{array}\right]
$$

Similarly, in the same way, element node forces can be obtained. Let $F$ be the 
element node force vector. Combining Equation (6), the matrix form can be written as follows

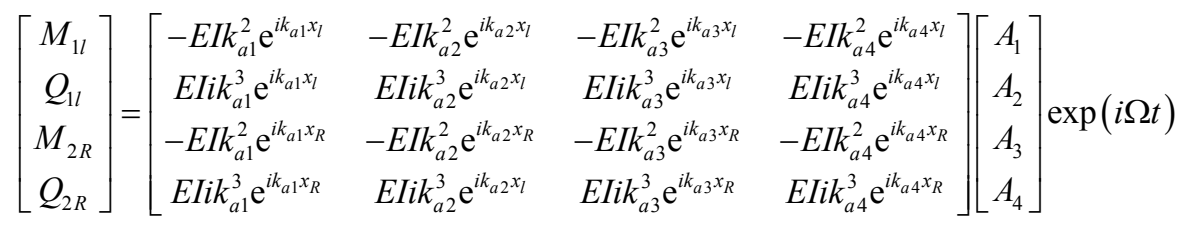

Equation (10) can be written in the following concise form

$$
\boldsymbol{F}_{e}=\boldsymbol{B} \boldsymbol{A}
$$

where:

$$
\boldsymbol{B}=\left[\begin{array}{llll}
E I k_{a 1}^{2} \mathrm{e}^{k_{a 1} x_{l}} & E I k_{a 2}^{2} \mathrm{e}^{k_{a 2} x_{l}} & E I k_{a 3}^{2} \mathrm{e}^{k_{a 3} x_{l}} & E I k_{a 4}^{2} \mathrm{e}^{k_{a 4} x_{l}} \\
E I k_{a 1}^{3} \mathrm{e}^{k_{a 1} x_{l}} & E I k_{a 2}^{3} \mathrm{e}^{k_{a 2} x_{l}} & E I k_{a 3}^{3} \mathrm{e}^{k_{a 3} x_{l}} & E I k_{a 4}^{3} \mathrm{e}^{k_{a 4} x_{l}} \\
E I k_{a 1}^{2} \mathrm{e}^{k_{a 1} x_{R}} & E I k_{a 2}^{2} \mathrm{e}^{k_{a 2} x_{R}} & E I k_{a 3}^{2} \mathrm{e}^{k_{a 3} x_{R}} & E I k_{a 4}^{2} \mathrm{e}^{k_{a 4} x_{R}} \\
E I k_{a 1}^{3} \mathrm{e}^{k_{a 1} x_{R}} & E I k_{a 2}^{3} \mathrm{e}^{k_{a 2} x_{l}} & E I k_{a 3}^{3} \mathrm{e}^{k_{a 3} x_{R}} & E I k_{a 4}^{3} \mathrm{e}^{k_{a 4} x_{R}}
\end{array}\right]
$$

From Equation (8), we can derive the column vector

$$
\boldsymbol{A}=\boldsymbol{C}^{-1} \boldsymbol{U}
$$

Substituting Equation (13) into Equation (11), and the following equation can be obtained

$$
\boldsymbol{F}_{e}=\boldsymbol{B} \boldsymbol{C}^{-1} \boldsymbol{U}
$$

Let $\boldsymbol{D}_{e}=\boldsymbol{B} \boldsymbol{C}^{-1}, \boldsymbol{D}_{e}$ is generally called the element dynamic stiffness matrix, which is a function of the tube vibration frequency $\Omega$. If the structure consists of only one element, the following equation can be used to calculate the frequency,

$$
D(\Omega)=\operatorname{det}\left|\boldsymbol{D}_{e}\right|=0
$$

Note: for different boundary conditions, Equation (15) has different forms, otherwise the wrong results will be obtained.

Here, the dynamic stiffness method and transfer matrix method are combined to analyze the dynamic characteristics of the pipeline. The dynamic stiffness matrix of a large element (per span) is calculated by the transfer matrix method. Assuming that the number of small elements in a large element is 40 , according to the previous theory, the dynamic stiffness matrix of the $i$-th small element is

$$
\left\{\begin{array}{l}
\boldsymbol{F}_{L} \\
\boldsymbol{F}_{R}
\end{array}\right\}_{i}=\left[\begin{array}{ll}
\boldsymbol{K}_{1} & \boldsymbol{K}_{2} \\
\boldsymbol{K}_{3} & \boldsymbol{K}_{4}
\end{array}\right]\left\{\begin{array}{l}
\boldsymbol{W}_{L} \\
\boldsymbol{W}_{R}
\end{array}\right\}, i=1,2, \cdots, n
$$

Based on the above equation, after proper mathematical processing, the element transfer matrix is obtained

$$
\left\{\begin{array}{l}
\boldsymbol{W}_{R} \\
\boldsymbol{F}_{R}
\end{array}\right\}_{i}=[\boldsymbol{T}]_{i}\left\{\begin{array}{l}
\boldsymbol{W}_{L} \\
\boldsymbol{W}_{R}
\end{array}\right\}_{i}=\left[\begin{array}{cc}
-\boldsymbol{K}_{2}^{-1} & -\boldsymbol{K}_{2}^{-1} \\
\boldsymbol{K}_{3}-\boldsymbol{K}_{4} \boldsymbol{K}_{2}^{-1} \boldsymbol{K}_{1} & -\boldsymbol{K}_{4} \boldsymbol{K}_{2}^{-1}
\end{array}\right]_{i}\left\{\begin{array}{l}
\boldsymbol{W}_{L} \\
\boldsymbol{W}_{R}
\end{array}\right\}_{i}, i=1,2 \cdots, n
$$

From the transfer matrix of the small element, the transfer matrix between the left value of the initial node of the large element and the end node is obtained, let 


$$
\left\{\begin{array}{l}
\boldsymbol{W}_{R} \\
\boldsymbol{F}_{R}
\end{array}\right\}=[\boldsymbol{T}]_{n}[\boldsymbol{T}]_{n-1} \ldots[\boldsymbol{T}]_{1}\left\{\begin{array}{l}
\boldsymbol{W}_{L} \\
\boldsymbol{F}_{L}
\end{array}\right\}_{1}=[\boldsymbol{T}]\left\{\begin{array}{c}
\boldsymbol{W}_{L} \\
\boldsymbol{F}_{L}
\end{array}\right\}_{1}
$$

The transfer matrix $T$ in Equation (18) is decomposed into displacement and force vectors.

After mathematical processing, the dynamic stiffness matrix of the large element is obtained.

$$
\left\{\begin{array}{c}
-\boldsymbol{F}_{L} \\
\boldsymbol{F}_{R}
\end{array}\right\}_{I}=\left[\begin{array}{cc}
\boldsymbol{T}_{2}^{-1} & -\boldsymbol{T}_{2}^{-1} \\
\boldsymbol{T}_{3}-\boldsymbol{T}_{4} \boldsymbol{T}_{2}^{-1} & -\boldsymbol{T}_{4} \boldsymbol{T}_{2}^{-1}
\end{array}\right]_{I}\left\{\begin{array}{l}
\boldsymbol{W}_{L} \\
\boldsymbol{W}_{R}
\end{array}\right\}_{I}, I=1,2, \cdots, 7
$$

where $I$ denotes a span element (large element).

Assuming that the structure is composed of many elements, we need to assemble the element stiffness matrix into the global dynamic stiffness matrix, and the processing method is similar to the usual finite element method. The following examples give calculation details.

\section{Analysis of Examples}

\subsection{Critical Velocity of Single-Span Straight-Pipe}

To verify the effectiveness of the proposed method, in the first example, the first fourth-order frequency of a simple-supported single-span infusion straight pipe is calculated. The calculation results in this paper will be compared with the results of previous studies [1]. Figure 1 shows a single-span simply-supported infusion pipe with a pipe length of $l=4 \mathrm{~m}$, where the material density of the pipe is $\rho_{p}=7850 \mathrm{~kg} / \mathrm{m}^{3}$, the Young's modulus is $E=200 \times 10^{9} \mathrm{~Pa}$, the external diameter of the pipe is $D=355.6 \mathrm{~mm}$, the thickness of the pipe wall is $t_{w}=9.0 \mathrm{~mm}$, the cross-section of the diameter of the tube is $I=\pi\left(d_{0}^{4}-d_{i}^{4}\right) / 64$ $=1.4726 \times 10^{-4} \mathrm{~m}^{4}$, the mass of pipe element is $m_{\rho}=76.9 \mathrm{~kg} / \mathrm{m}$, and the mass of fluid in pipe element is $m_{f}=\rho_{f} A=89.5 \mathrm{~kg} / \mathrm{m}$. According to the existing literature, when the internal flow velocity increases, the natural frequency of the system becomes smaller. When the flow velocity is large enough, the first-order natural frequency drops to zero and buckling instability occurs. At this time, the velocity is the critical velocity. To obtain the natural frequency and critical speed, the pipe is divided into 4 elements with a length of $l / 4$ and 5 nodes.

From the previous theory, the global stiffness matrix of the pipe is assembled from the element stiffness matrix $\boldsymbol{D}_{i}(i=1,2,3,4)$. In this example, the simply supported boundary condition is expressed as

$$
\left\{\begin{array}{l}
w_{1}=w_{5}=0 \\
\theta_{1} \neq 0, \theta_{5} \neq 0
\end{array}\right.
$$

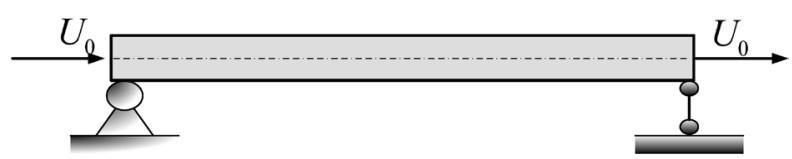

Figure 1. Single-span simple support pipe. 


$$
\left\{\begin{array}{l}
Q_{1} \neq 0, Q_{5} \neq 0 \\
M_{1}=M_{5}=0
\end{array}\right.
$$

Substituting the above expressions (20) and (21) into equation (15), the natural frequency equation is changed to the following form

$$
K(\Omega)=\operatorname{det}|\boldsymbol{G}|=0
$$

where $\boldsymbol{G}$ is the matrix obtained by the simplification of the global stiffness matrix $\boldsymbol{D}$ by applying the boundary condition (20) (21). The author is limited to space, and this expression is omitted.

For better comparison with other scholars' literature results, several dimensionless parameters are defined

$$
u=\left(\frac{M}{E I}\right)^{\frac{1}{2}} U L, \beta=\frac{m_{f}}{m_{f}+m_{\rho}}, \omega=\sqrt{\frac{m_{f}+m_{\rho}}{E I}} L^{2} \Omega
$$

The first three-order natural frequency of a single-span simply-supported infusion tube as a function of flow rate is shown in Figure 2(a). Figure 2(a) shows the effect of the internal fluid velocity on the natural frequency of the first three orders of the system. Based on the above algorithm, the obtained critical velocity of the fluid is $u_{c r}=3.1415$, and the critical velocity of the simply supported infusion pipe is $u_{c r}=\pi$ [1], so the results obtained by the current algorithm have good consistency with the literature analysis results.

Similarly, based on this method, the relationship between the flow velocity and frequency of the pipe conveying fluid under other boundary conditions can also be obtained. Note that in the actual calculation, equations (20) and (21) need to be changed according to different boundary conditions. Figure 2(b) shows the first three order frequencies of the clamped support pipe based on this algorithm.

To better compare the algorithms in this paper, when the flow velocity is $u=$ 0 , the pipe becomes a straight beam and the natural frequency of the pipe can be analyzed. For comparison, when $u=0$ is considered, the first four-order dimensionless frequency calculated in this paper are compared with the DQM solution and the true analytical solution [24], as shown in Table 2. As can be seen from Table 2, the accuracy of the results obtained in this paper is very high. The algorithm in this paper can also be applied to vibration analysis of other boundary conditions of single-span in pipe conveying fluid.

\subsection{Multi-Span Pipe Conveying Fluid}

Figure 3 shows the multi-span intermediate simply supported pipe conveying fluid model under two different working conditions. In Figure 3, the total length of the pipe is $L=40 \mathrm{~m}$ with 7 spans in which the length of each span is $l_{i}(i=1,2,3,4,5,6)$. Let $l_{1}=4 \mathrm{~m}, l_{2}=4 \mathrm{~m}, l_{3}=4 \mathrm{~m}, l_{4}=16 \mathrm{~m}, l_{5}=4 \mathrm{~m}$, $l_{6}=4 \mathrm{~m}, l_{7}=4 \mathrm{~m}$, so that is a non-period pipe. The other data of the pipe conveying fluid are consistent with the data of the single-span pipe conveying fluid 

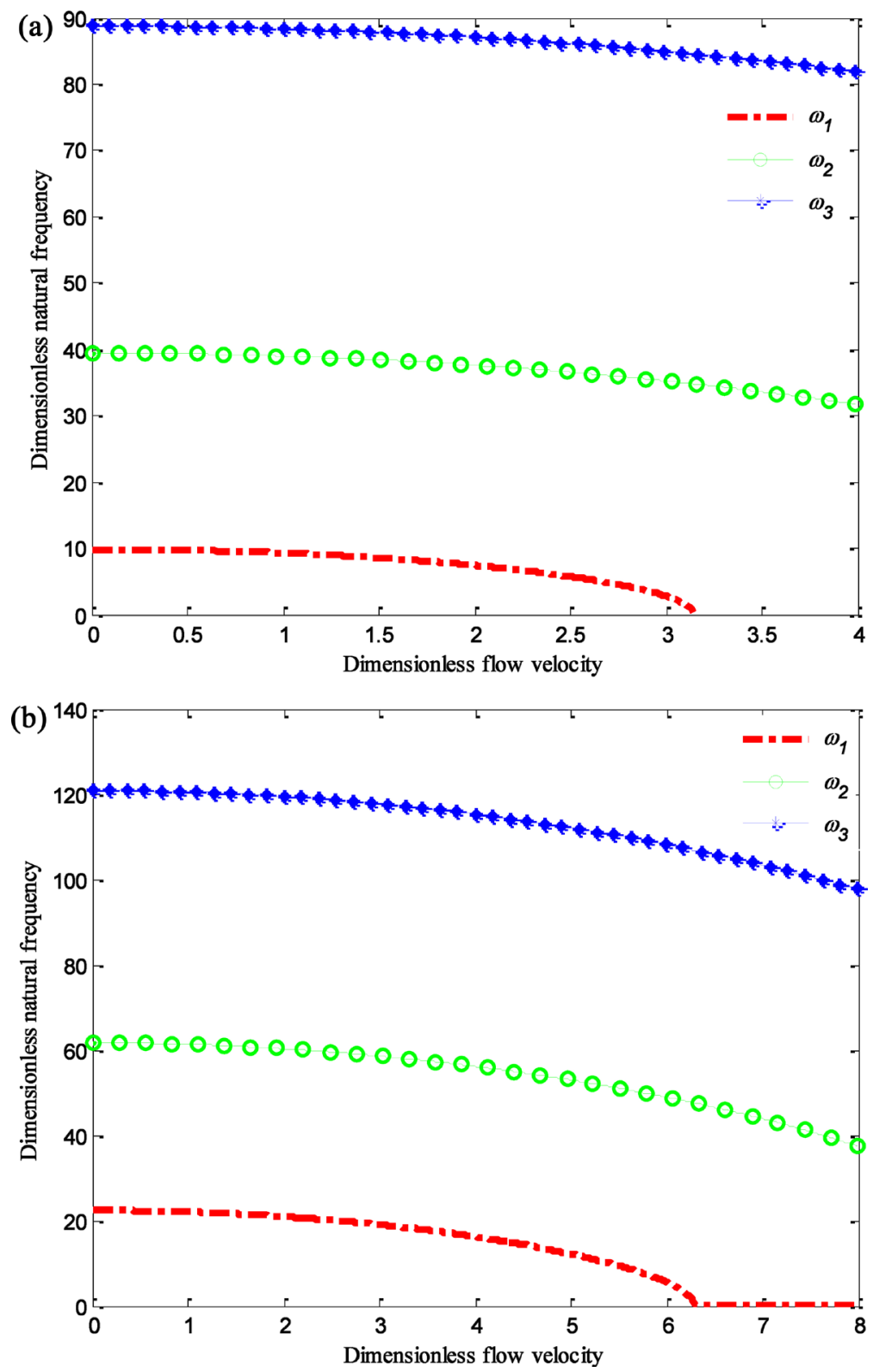

Figure 2. Effects of fluid velocity on the natural frequencies. (a) The first-third order frequency of a simply supported pipe; (b) First third-order frequency of clamped support pipe.

Table 2. Natural frequency of the pipe conveying fluid at flow velocity $u=0$.

\begin{tabular}{cccccc}
\hline Boundary conditions & algorithm & $\omega_{1}$ & $\omega_{2}$ & $\omega_{3}$ & $\omega_{4}$ \\
\hline simply support & present & 9.8696 & 39.4784 & 88.8264 & 157.9137 \\
& DQM & 9.8716 & 39.4863 & 88.8442 & 157.9454 \\
& Analytical solution & 9.8696 & 39.4784 & 88.8264 & 157.9137 \\
clamped support & present & 27.3733 & 61.6728 & 120.9034 & 199.8594 \\
& DQM & 22.3778 & 61.6852 & 120.9276 & 199.8995 \\
& Analytical solution & 27.3733 & 61.6728 & 120.9034 & 199.8594 \\
\hline
\end{tabular}


in section 3.1 of this article. Figure 3(b) shows the clamped support on both sides, with a total length of $L=40 \mathrm{~m}$ and a total of 10 spans. Each span has a length of $l_{i}=4 \mathrm{~m}(i=1,2,3,4,5,6,7,8,9,10)$, that is, a periodic span.

This article studies Figure 3(a) first. Assume that each span is a large element with a total of 7 large elements, and then the pipe is divided into 40 small elements with a length of $1 \mathrm{~m}$. The processing of calculating the dynamic stiffness matrix of large element (per span) is similar to Section 3.1.

In the actual calculation, it should be noted that because the length of the span element is different, the calculated span-element dynamic stiffness matrix is different. After the element dynamic stiffness matrix is obtained, it is assembled into the global stiffness matrix according to the previous idea, and then the natural frequency and the critical velocity of instability can be calculated by applying the simple support condition.

Table 3 shows the first five order dimensional natural frequencies of the simply supported system at both sides of the type of Figure 3(a) at different flow velocity. Figure 4(a) shows the relationship between the flow velocity $U_{0}$ and the first two order frequencies of the system, which is based on the data listed in Table 3 .

From Figure 2(a), the continuously increasing flow velocity $U_{0}$ reduces the natural frequency of the system. The impact of the flow velocity $U_{0}$ on the system's

(a)
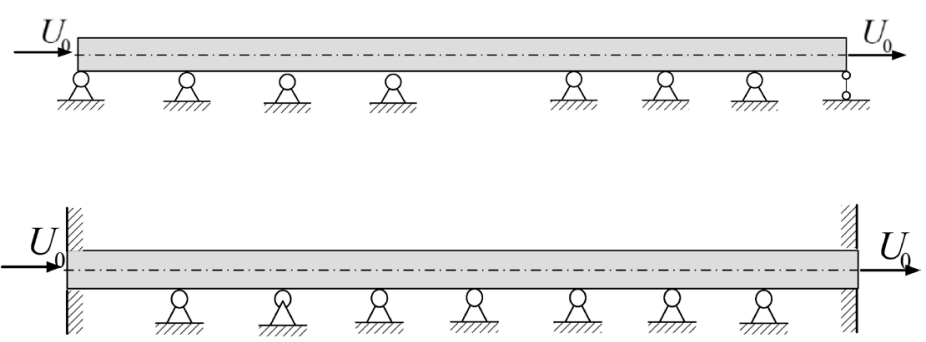

(b)

Figure 3. Model of multi-span the pipe conveying fluid. (a) Non-period support both pined-pined ends; (b) Period support with clamped-clamped ends.

Table 3. Effect of fluid velocity on the first five natural frequencies.

\begin{tabular}{cccccc}
\hline \multirow{2}{*}{$\begin{array}{c}\text { Flow velocity } \\
U_{0}\end{array}$} & $\omega_{1}$ & $\omega_{2}$ & $\omega_{3}$ & $\omega_{4}$ & $\omega_{5}$ \\
\cline { 2 - 6 } & 29.8729 & 84.6254 & 167.5864 & 259.3869 & 274.0480 \\
0.0 & 29.4345 & 84.1936 & 167.1276 & 258.9441 & 273.5749 \\
30 & 28.0996 & 82.8921 & 165.7491 & 257.2281 & 271.7400 \\
60 & 26.6814 & 81.5341 & 164.3128 & 255.4375 & 269.8285 \\
80 & 24.8009 & 79.7723 & 162.4559 & 253.1184 & 267.3579 \\
100 & 20.9732 & 76.3603 & 158.8626 & 248.6189 & 262.5803 \\
130 & 15.5063 & 71.8903 & 154.2619 & 242.8382 & 258.4737 \\
160 & 6.0670 & 66.2903 & 148.5919 & 235.6913 & 248.9730 \\
190 & & & & & \\
\hline
\end{tabular}



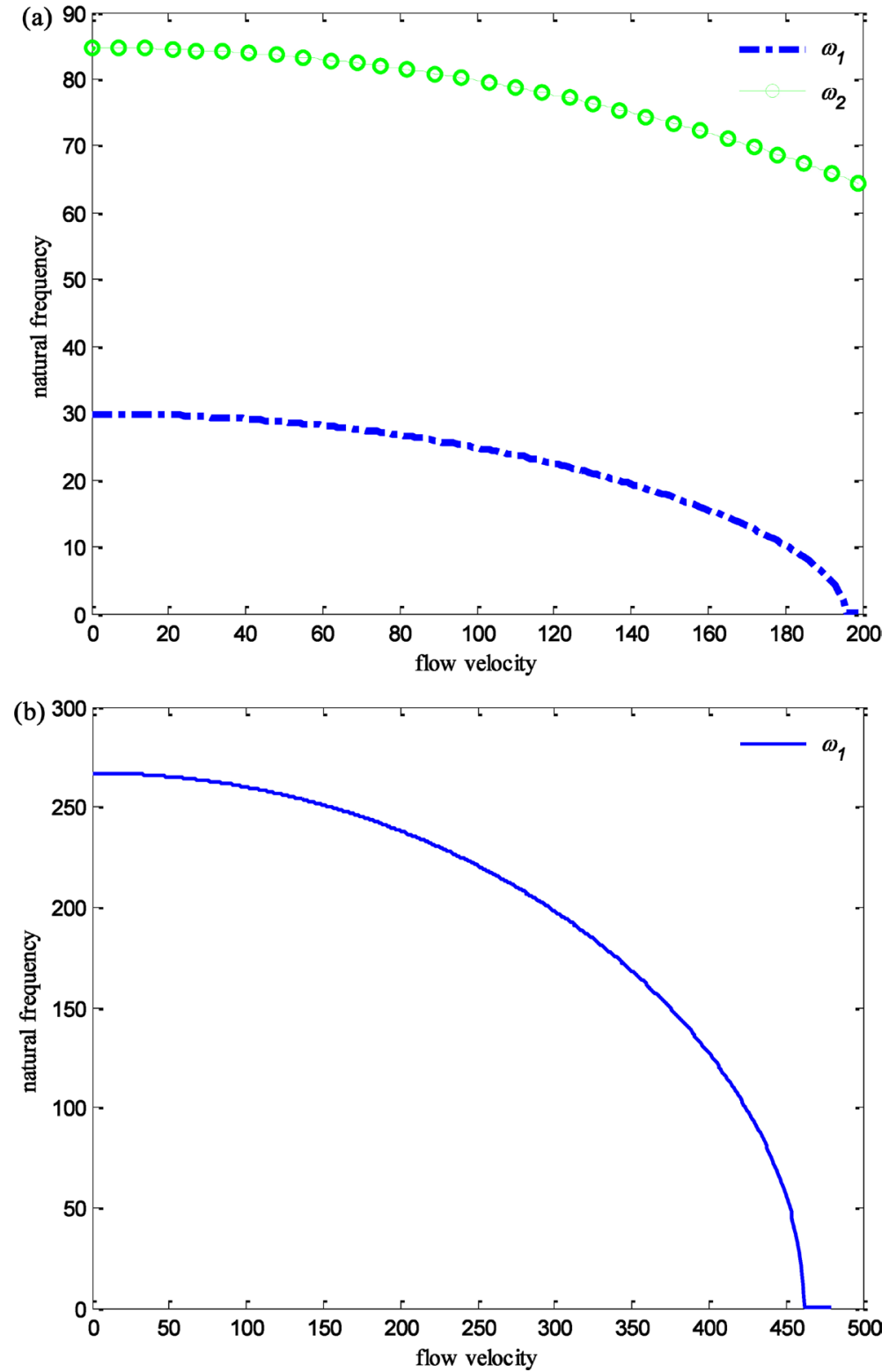

Figure 4. Effect of fluid velocity on the natural frequencies. (a) First two order frequencies of non-uniform multi-span with simply supported at both sides; (b) First-order frequency of uniform multi-span pipe with clamped support on both sides.

first-order frequency $\omega_{1}$ greatly exceeds the other natural frequencies, and when the velocity $U_{0}=195.702 \mathrm{~m} / \mathrm{s}$, the first-order frequency approaches zero. This means that when the velocity $U_{0}$ exceeds $195.702 \mathrm{~m} / \mathrm{s}$, buckling instability occurs in the inhomogeneous multi-span simply supported pipe conveying fluid [1].

For the same reason, a similar method can be used for Figure 3(b), but it should be noted that the application of boundary conditions should be different from the foregoing. Figure 4(b) shows the relationship between the flow velocity $U_{0}$ of the simply supported system at both sides and the first two order frequencies of the system. The critical velocity of the first-order frequency close to zero is $U_{0}=461.61 \mathrm{~m} / \mathrm{s}$. 


\section{Conclusions}

In this article, the dynamic stiffness element method based on Euler beam is used to analyze the free vibration of the pipes conveying fluid. The method in this paper has a strong practical application background. It can be used to analyze the vibration of single-span pipes conveying fluid with different boundary conditions, as well as periodic and non-periodic multi-span pipes conveying fluid.

1) The results of the natural frequency and critical velocity of the single-span pipes were compared with the results of DQM and other literature, and good agreement was achieved. By combining the dynamic stiffness method with the transfer matrix method, the natural frequency and critical velocity of the multi-span pipes conveying fluid are obtained.

2) In the calculation example given, the multi-span is closer to the actual engineering problem. Under the condition of simple support, the corresponding dynamic stiffness matrix is obtained, and its natural frequency and critical flow velocity of instability are analyzed. It can be concluded that the continuously increasing flow velocity reduces the natural frequency of the system and has the greatest effect on the first-order frequency. When the system flow velocity exceeds the critical flow velocity of instability, the inhomogeneous multi-span simply supported pipe conveying fluid will buckle and instability.

3) The current work demonstrates that the dynamic stiffness element method can deal with simple and more complex conditions of the pipes conveying fluid, and supplements the application environment of the dynamic stiffness method and transfer matrix.

\section{Acknowledgements}

This work was partly supported by the National Natural Science Foundation of China (No. 11872043), the Opening Project of Sichuan Province University Key Laboratory of Bridge Non-destruction Detecting and Engineering Computing (No. 2016QZJ03), Fund project of Sichuan University of Science \& Engineering in hit-haunting for talents (No. 2016RCL31), Fund project of Sichuan Provincial Department of Education (No. 18ZA0353).

\section{Conflicts of Interest}

The authors declare no conflicts of interest regarding the publication of this paper.

\section{References}

[1] Paidoussis, M.P. (2000) Fluid-Structure Interactions: Slender Structure and Axial Flow, Volume 1. Elsevier, Academic Publishers, London.

[2] Paidoussis, M.P. (1974) Dynamic Stability of Pipes Conveying Fluid. Journal of Sound and Vibration, 33, 267-294. https://doi.org/10.1016/S0022-460X(74)80002-7

[3] Jin, J.D. and Song, Z.Y. (2005) Parametric Resonances of Supported Pipes Convey- 
ing Pulsating Fluid. Journal of Fluid and Structure, 20, 763-783.

https://doi.org/10.1016/j.jfluidstructs.2005.04.007

[4] Zhang, L. (1999) FSI Analysis of Liquid-Filled Pipes. Journal of Sound and Vibration, 224, 69-99. https://doi.org/10.1006/jsvi.1999.2158

[5] Huang, Y.M., Liu, Y.S. and Li, B.-H. (2010) Natural Frequency Analysis of Fluid Conveying Pipeline with Different Boundary Conditions. Nuclear Engineering and Design, 240, 461-467. https://doi.org/10.1016/j.nucengdes.2009.11.038

[6] Lee, U., Jang, I. and Go, H. (2009) Stability and Dynamic Analysis of Oil Pipelines by Using Spectral Element Method. Journal of Loss Prevention in the Process Industries, 22, 873-878. https://doi.org/10.1016/j.jlp.2008.08.002

[7] Ni, Q., Zhang, Z.L. and Wang, L. (2011) Application of the Differential Transformation Method to Vibration Analysis of Pipes Conveying Fluid. Applied Mathematics and Computation, 217, 7028-7038. https://doi.org/10.1016/j.amc.2011.01.116

[8] Sreejith, B., Jayaraj, K. and Ganesan, N. (2004) Finite Element Analysis of Fluid-Structure Interaction in Pipeline Systems. Nuclear Engineering and Design, 227, 313-322. https://doi.org/10.1016/j.nucengdes.2003.11.005

[9] Ni, Q., Huang, Y.-Y. and Chen, Y.-P. (2001) Differential Quadrature Method for Analyzing Critical Flow Velocity of the Pipe Conveying Fluid with Spring Support. Chinese Journal of Computational Mechanics, 8, 146-149.

[10] Wu, J.S. and Shin, P.Y. (2001) The Dynamic Analysis of Multispan Fluid-Conveying Pipe Subjected to External Load. Journal of Sound and Vibration, 239, 201-215. https://doi.org/10.1006/jsvi.2000.3119

[11] Chen, Z.X. and Zhang, W.H. (1993) Stability and Dynamic Response of Multi-Span Fluid-Conveying Pipes. The Ocean Engineering, 15, 1-8.

[12] Xü, W.-H., Xie, W.D., Gao, X.F. and Ma, Y.X. (2017) Study on Vortex-Induced Vibrations (VIV) of Multi-Spans Pipelines. Journal of Ship Mechanics, 21, 1025-1034.

[13] Deng, J., Liu, Y. and Liu, W. (2017) Size-Dependent Vibration Analysis of Multi-Span Functionally Graded Material Micropipes Conveying Fluid Using a Hybrid Method. Microfluidics and Nanofluidics, 21, 133. https://doi.org/10.1007/s10404-017-1967-7

[14] Zhao, Q., Xu, Q., Yao, H.L. and Wen, B.C. (2016) Stability of a Multi-Span Rotor System with Fluid-Induced Self-Excited Vibration. Journal of Vibration and Shock, 35, 196-200.

[15] Fang, X.J., Zu, H.B., Xiong, Z.Q., Zhang, K.F. and Xie, Y.C. (2017) Experimental Study on Flow-Induced Vibration of Multi-Span Tube Bundle with Tube Support Plate. Atomic Energy Science and Technology, 51, 1379-1386.

[16] Guebailia, M. and Ouelaa, N. (2017) Free Vibration of a Multi-Span Road Bridge Supported by Point Elastic Supports. In: Haddar, M., Chaari, F., Benamara, A., Chouchane, M., Karra, C. and Aifaoui, N., Eds., Design and Modeling of Mechanical Systems-III. CMSM 2017. Lecture Notes in Mechanical Engineering, Springer, Cham, 91-96. https://doi.org/10.1007/978-3-319-66697-6_10

[17] Deng, J., Liu, Y., Zhang, Z. and Liu, W. (2017) Size-Dependent Vibration and Stability of Multi-Span Viscoelastic Functionally Graded Material Nanopipes Conveying Fluid Using a Hybrid Method. Composite Structures, 179, 590-600. https://doi.org/10.1016/j.compstruct.2017.07.084

[18] Lu, G., Wang, M., Wang, B., Cao, R. and Liu, Y. (2018) Indirect Inverse Substructuring Identification Method for Coupling Dynamic Stiffness of Vibrational Structures. Acta Acustica, 43, 372-380. 
[19] Dan, D., Han, F., Cheng, W. and Xu, B. (2019) Unified Modal Analysis of Complex Cable Systems via Extended Dynamic Stiffness Method and Enhanced Computation. Structural Control and Health Monitoring, 26, e2435.

https://doi.org/10.1002/stc.2435

[20] Peplow, A.T. (2018) Computation of a Well-Conditioned Dynamic Stiffness Matrix for Elastic Layers Overlying a Half-Space. Journal of Physics Conference Series, 1106, Article ID: 012035. https://doi.org/10.1088/1742-6596/1106/1/012035

[21] Zuo, W.J., Ma, H.G., Gui, C.Y. and Li, H. (2017) Lightweight Design of Bus Frame Constrained by Static and Dynamic Stiffness. Journal of South China University of Technology, 45, 7-12.

[22] Li, B.-H., Gao, H.-S., Zhai, H.-B., Liu, Y.-S. and Yue, Z.-F. (2011) Free Vibration Analysis of Multi-Span Pipe Conveying Fluid with Dynamic Stiffness Method. Nuclear Engineering and Design, 241, 666-671.

https://doi.org/10.1016/j.nucengdes.2010.12.002

[23] Yuan, S., Ye, K.-S., Williams, F.W. and Kennedy, D. (2005) Theory and Algorithm of the Exact Method for Free Vibration Problems of Skeletal Structures. Engineering Mechanics, 22, 1-8.

[24] Thomson, W.T. (1998) Theory of Vibration with Applications. Unwin Hyman Ltd., London. 